\title{
Electrochemical Detection of Phosphate Ion in Body Fluids with a Magnesium Phosphate Modified Electrode
}

\author{
Qixuan Chen, Shuquan Sun, Guoxia Ran, Chan Wang, Wenxiu Gu, and Qijun Song ${ }^{\dagger}$ \\ International Research Center for Photoresponsive Molecules and Materials, School of Chemical and \\ Material Engineering, Jiangnan University, 1800 Lihu Road, Wuxi, Jiangsu 214122, P. R. China
}

\begin{abstract}
An electrochemical sensor for phosphate detection in body fluids was developed based on the hydration transition of magnesium hydrogen phosphate (newberyite, $\mathrm{MgHPO}_{4} \cdot 3 \mathrm{H}_{2} \mathrm{O}$ ). The sensor was fabricated through incubation of a multiwalled carbon nanotube/Nafion (MWCNT/Nafion) modified glassy carbon electrode (GCE) in magnesium phosphate solution, where $\mathrm{MgHPO}_{4} \cdot 3 \mathrm{H}_{2} \mathrm{O}$ was self-assembled on the electrode surface (denoted as $\mathrm{MgP} / \mathrm{MWCNT} / \mathrm{Nafion}$ ). An electrooxidation peak at $1.0 \mathrm{~V} v s . \mathrm{Ag} / \mathrm{AgCl}$ was observed when the as-prepared electrode was subjected to a differential pulse voltammetry (DPV) scan in the presence of phosphate in acetate solution. When the DPV scan was performed in $0.4-1.3 \mathrm{~V} v$ s. $\mathrm{Ag} / \mathrm{AgCl}$, a linear relationship was observed between the peak height and the phosphate concentration in the range from 0.01 to $25 \mu \mathrm{M}$ in the presence of $0.1 \mathrm{mM} \mathrm{Mg}^{2+}$ in the acetate solution with a limit of detection of $32 \mathrm{nM}$. And the sensor was successfully applied for phosphate detection in human urine and saliva samples with recoveries of $94.7-104.4$ and $96-103.3 \%$, respectively.
\end{abstract}

Keywords Electrochemical sensor, phosphate ion, body fluids, hydration, magnesium phosphate

(Received November 20, 2020; Accepted February 11, 2021; Advance Publication Released Online by J-STAGE February 19, 2021)

\section{Introduction}

The electrochemical detection of phosphate ions in body fluids has attracted a great deal of interest recently due to its real-time, in-situ detection capabilities, portable instrumentation and low cost of analysis. ${ }^{1,2}$ The electrochemical inertness of phosphate ion, however, presents considerable challenges to direct methods of detection, hence many indirect strategies have been proposed for phosphate sensing. Ion selective electrodes, ${ }^{3}$ enzyme-based electrochemical biosensors, ${ }^{4,5}$ amperometric sensors $^{6-8}$ and voltammetry sensors ${ }^{9-11}$ have been developed in recent years. In the last case, some direct strategies for phosphate detection under auxiliary steady atmosphere supply were also developed. For instance, the reaction of phosphate with molybdate was utilized to realize the detection of phosphate. ${ }^{12}$ Based on the catalytic hydrogen waves, molybdenum phosphide (MoP) modified electrode was fabricated for the detection of phosphate in blood. These methods have shown the feasibility of phosphate detection with electrochemical sensors. However, some intrinsic disadvantages were also witnessed. For example, the detections are often influenced by the dissolved oxygen and their limit of detection is still not high enough for body fluidic analysis. ${ }^{13}$

In our recent work, an electrochemical sensor for the detection of phosphate in environmental samples was developed based on an intriguing redox behavior observed from calcium phosphate $(\mathrm{CaP})$ modified electrode. ${ }^{14}$ It was understood that phosphate could tune the generation of coordinated water in the calcium phosphates, which is responsible for the appearance of the

$\dagger$ To whom correspondence should be addressed.

E-mail: qsong@jiangnan.edu.cn oxidation peak at relatively low voltage $(1.0 \mathrm{~V}$ vs. $\mathrm{Ag} / \mathrm{AgCl})$. Calcium ion was found to be able to promote the electrochemical oxidation peak, hence can enhance the sensitivity of detection. However, it was also noted that $\mathrm{Ca}^{2+}$ can easily precipitate with phosphate ion at increased concentration, so the promotion effect of $\mathrm{Ca}^{2+}$ is restricted to some extent. To overcome this limitation, magnesium ion $\left(\mathrm{Mg}^{2+}\right)$ was considered in the present work. $\mathrm{Mg}^{2+}$ has greater charge density than that of $\mathrm{Ca}^{2+}$ ion, ${ }^{15}$ hence it could have a stronger enhancement effect on the hydrolysis of the coordinated $\mathrm{H}_{2} \mathrm{O}$. This assumption has been evidenced by the fact that $\mathrm{Mg}^{2+}$-coordinated $\mathrm{H}_{2} \mathrm{O}$ has stronger acidity $\left(\mathrm{p} K_{\mathrm{a}}=11.4\right)$ than that of $\mathrm{Ca}^{2+}$-coordinated $\mathrm{H}_{2} \mathrm{O}\left(\mathrm{p} K_{\mathrm{a}}=\right.$ 12.67). ${ }^{16}$ The free energy required to deprotonate a coordinated $\mathrm{H}_{2} \mathrm{O}$ in the presence of $\mathrm{Mg}^{2+}$ ion is only $40 \%$ of that required to deprotonate a free $\mathrm{H}_{2} \mathrm{O} .{ }^{17}$ These observations indicate that $\mathrm{Mg}^{2+}$ ion can promote the ionization of water, i.e., under the modulation of $\mathrm{Mg}^{2+}$, and the proton of coordinated $\mathrm{H}_{2} \mathrm{O}$ is prone to be donated to phosphate. The ionization of the coordinated $\mathrm{H}_{2} \mathrm{O}$ would facilitate the oxygen release during the subsequent voltage scan. Furthermore, the relatively high solubility of magnesium phosphates (MgP) should have less likelihood to form precipitation in bulk solution, hence $\mathrm{MgP}$ production is more localized in the electrode surface. ${ }^{18-21}$ Therefore, it is expected that the sensitivity of the MgP-based phosphate sensor could be further enhanced in the presence of $\mathrm{Mg}^{2+}$.

In our previous work, a composite of Nafion and MWCNT was used for the assembly of $\mathrm{CaP}$ on the electrode surface, where singlet oxygen production was evidenced by the accompanied electrochemiluminescence. ${ }^{22}$ Nafion has an excellent ion exchange property ${ }^{23,24}$ and MWCNT can effectively improve the conductivity of the modified electrode, so the composite is often used for electrode modification to expand 
surface area and to improve the electrochemical performance. ${ }^{25,26}$ Therefore, a composite of Nafion and MWCNT was adopted in the present work to modify the glassy carbon electrode (GCE) and the coated layer acted as the substrate for the assembly of $\mathrm{MgP}$. The electrochemical sensor, denoted as MgP/MWCNT/ Nafion, was obtained by sequentially incubating the MWCNT/ Nafion electrode in $\mathrm{Mg}^{2+}$ and phosphate solution. The $\mathrm{MgP}$ assembled on the electrode surface were comprehensively studied before and after voltage application. And the oxidation of coordinated $\mathrm{H}_{2} \mathrm{O}$ originated from hydration of $\mathrm{MgP}$ and the effect of $\mathrm{Mg}^{2+}$ on the electrochemical oxidation of coordinated $\mathrm{H}_{2} \mathrm{O}$ was comprehensively investigated. Finally, the as-prepared sensor (MgP/MWCNT/Nafion) was validated by successful determination of phosphate contents in urine and saliva samples.

\section{Experimental}

\section{Materials}

Multi-walled carbon nanotube (thin and short, 755117 Aldrich, purity $95 \%$ ) and Nafion (perfluorinated ion exchange polymer) solution were obtained from Sigma-Aldrich. Magnesium chloride hexahydrate $\left(\mathrm{MgCl}_{2} \cdot 6 \mathrm{H}_{2} \mathrm{O}\right)$, sodium hydrogen phosphate $\left(\mathrm{Na}_{2} \mathrm{HPO}_{4} \cdot 12 \mathrm{H}_{2} \mathrm{O}\right)$, sodium dihydrogen phosphate $\left(\mathrm{NaH}_{2} \mathrm{PO}_{4} \cdot 2 \mathrm{H}_{2} \mathrm{O}\right)$, sodium hydroxide, sodium acetate, isopropanol (IPA), dimethyl formamide (DMF) and other chemicals were purchased from Sinopharm Chemical Reagent Co., Ltd. (Shanghai, China). All the chemicals were of analytical grade and used without further purification. All solutions were prepared with ultra-pure water $(18.2 \mathrm{M} \Omega \cdot \mathrm{cm})$, which was obtained from a Milli-Q Plus water purification system (Millipore, USA).

\section{Characterization}

Scanning electron microscopy (SEM) and energy dispersive spectrometer (EDS) images were obtained on a SUPRA 55 field emission scanning electron microscope (Carl Zeiss AG, Germany). Transmission electron microscope (TEM) images were acquired from a Hitachi $\mathrm{H}-600$ with $120 \mathrm{kV}$ accelerating voltage. The high-resolution transmission electron microscopy (HR-TEM) images were collected on a JEM-2010 instrument at $200 \mathrm{kV}$ accelerating voltage. Raman spectra were obtained from a Renishaw In Via confocal Raman microscope with $785 \mathrm{~nm}$ laser excitation. X-ray diffraction (XRD) was carried out on a D8 ADVANCE diffractometer (Bruker AXS, Germany) using $\mathrm{Cu} K \alpha$ radiation as the irradiation source. Inductively coupled plasma mass spectrometry (ICP-MS, ICAP TQ, Thermo Fisher Scientific Inc, Germany) was used to confirm the phosphate concentration in the body fluid. Fourier transform infrared spectroscopy (FTIR, Nicolet 6700, Thermo Fisher Scientific Co., Ltd., USA) was applied for the identification of the $\mathrm{MgP}$. The transmittance of the sample was recorded with 16 scans with resolution of $4 \mathrm{~cm}^{-1}$ between 550 and $4000 \mathrm{~cm}^{-1}$.

\section{Electrochemical measurements}

A CHI 660D electrochemical workstation (Shanghai Chenhua Apparatus Corporation, China) was used for all electrochemical measurements. A conventional three electrode system was employed to carry out the differential pulse voltammetry (DPV) investigations. Platinum wire was used as the counter electrode, $\mathrm{Ag} / \mathrm{AgCl}$ (saturated $\mathrm{KCl}$ ) was used as the reference electrode (RE), and MgP/MWCNT/Nafion was used as the working electrode (WE). DPV was scanned from 0.4 to $1.3 \mathrm{~V}$ at potential increments of $4 \mathrm{mV}$. Pulse width and pulse heightwere $0.2 \mathrm{~s}$ and $0.05 \mathrm{~V}$, respectively. Interval was $2 \mathrm{~s}$ and time of current measurement was $112.5 \mathrm{~s}$. The electrochemical process study of the MgP/MWCNT/Nafion electrode was carried out either in $0.1 \mathrm{M}$ PBS solution or $1.0 \mathrm{mM}$ sodium acetate solution. As the enhancement agent, $0.1 \mathrm{mM} \mathrm{Mg}{ }^{2+}$ was added in the acetate buffer for phosphate detection and the $\mathrm{pH}$ of the solution was adjusted to 9.0 with $0.1 \mathrm{M} \mathrm{NaOH}$. All tests were conducted at room temperature $\left(25^{\circ} \mathrm{C}\right)$.

\section{Preparation of MgP/MWCNT/Nafion modified electrode}

The route for $\mathrm{MgP} / \mathrm{MWCNT} / \mathrm{Nafion}$ preparation is shown in Scheme S1. Before the electrode modification, the glassy carbon electrode was subsequently polished with 0.3 and $0.5 \mu \mathrm{M}$ alumina slurry, then rinsed respectively in ethanol and ultrapure water for three times to clean away the remaining polishing powders and impurities.

The MWCNT/Nafion suspension was prepared by adding an amount of $75 \mathrm{mg}$ MWCNT in a $50 \mathrm{~mL}$ centrifuge tube containing $2.5 \mathrm{~mL}$ DMF, $2.5 \mathrm{~mL}$ Nafion and $20 \mathrm{~mL}$ IPA. The mixture was subjected to $30 \mathrm{~min}$ vortex mixing and $30 \mathrm{~min}$ ultrasound treatment respectively to obtain the $3 \mathrm{mg} / \mathrm{mL}$ MWCNT/Nafion suspension. These treatments may be repeated several times until MWCNT are evenly dispersed in the suspension. Then the polished electrode was drip-coated with $5 \mu \mathrm{L}$ MWCNT/Nafion suspension and allowed to dry in a clean environment at room temperature. For $\mathrm{MgP}$ modification, the MWCNT/Nafion modified electrode was inserted into a solution containing $0.1 \mathrm{M}$ magnesium chloride solution ( $\mathrm{pH} \mathrm{10)}$ for $24 \mathrm{~h}$ to adsorb $\mathrm{Mg}^{2+}$. Finally, the $\mathrm{Mg}^{2+} / \mathrm{MWCNT} / \mathrm{Nafion}$ was incubated in $0.1 \mathrm{M}$ phosphate buffer solution $(\mathrm{pH} 7.4)$ at $37.5^{\circ} \mathrm{C}$ for five days to obtain the MgP/MWCNT/Nafion electrode.

Determination of the phosphate concentration in urine and saliva The MgP/MWCNT/Nafion electrode was applied to determine the phosphate concentration in human urine and saliva samples. Before the electrochemical measurement, urine and saliva samples were diluted 4000 and 1500 times, respectively, with ultrapure water so that the phosphate concentrations fall in the linear range of calibration. In order to validate the results obtained from the $\mathrm{MgP} / \mathrm{MWCNT/Nafion}$ sensor, the ICP-MS analysis of phosphate was also conducted on the same samples.

\section{Results and Discussion}

\section{Preparation and characterization of $\mathrm{MgP} / \mathrm{MWCNT/Nafion}$}

As described in the Experimental section, the MgP/MWCNT/ Nafion was prepared by subsequently inserting the MWCNT/ Nafion electrode in $\mathrm{Mg}^{2+}$ and phosphate solution to assemble $\mathrm{MgP}$ on the electrode surface. The morphology and structure of $\mathrm{MgP}$ after five days of incubation were characterized. The SEM image (Fig. 1a) shows that the MgP formed on the electrode are uniformly distributed particles, which are similar to the morphology reported for $\mathrm{MgHPO}_{4} \cdot 3 \mathrm{H}_{2} \mathrm{O} .{ }^{27,28}$ Figure $1 \mathrm{~b}$ presents the TEM image of the continuous layer formed on the MWCNT/ Nafion. The HRTEM image (Fig. 1c) shows the lattice fringes of $0.363 \mathrm{~nm}$ and electron diffraction pattern presented in the inset of Fig. 1c can be attributed to the (022), (040) planes of $\mathrm{MgHPO}_{4} \cdot 3 \mathrm{H}_{2} \mathrm{O}$. Figure 1d shows the FTIR spectrum of the MgP. The absorption peaks at $3254 \mathrm{~cm}^{-1}$ with $v_{1}$ symmetric stretching and $1643 \mathrm{~cm}^{-1}$ with $v_{2}$ bend can be ascribed to structural water of $\mathrm{MgHPO}_{4} \cdot 3 \mathrm{H}_{2} \mathrm{O}$. The typical phosphate bands are observed at 1161, 1054 and 1014 with asymmetric stretching $v_{3}$ bending mode. ${ }^{29,30}$ The typical Raman shifts at $v_{1}$ $\mathrm{PO}_{4}{ }^{3-} 893$ and $983 \mathrm{~cm}^{-1}$ in Fig. 1e also confirm the formation of $\mathrm{MgHPO}_{4} \cdot 3 \mathrm{H}_{2} \mathrm{O}$ in the assembled products. ${ }^{31,32}$ The result agrees 

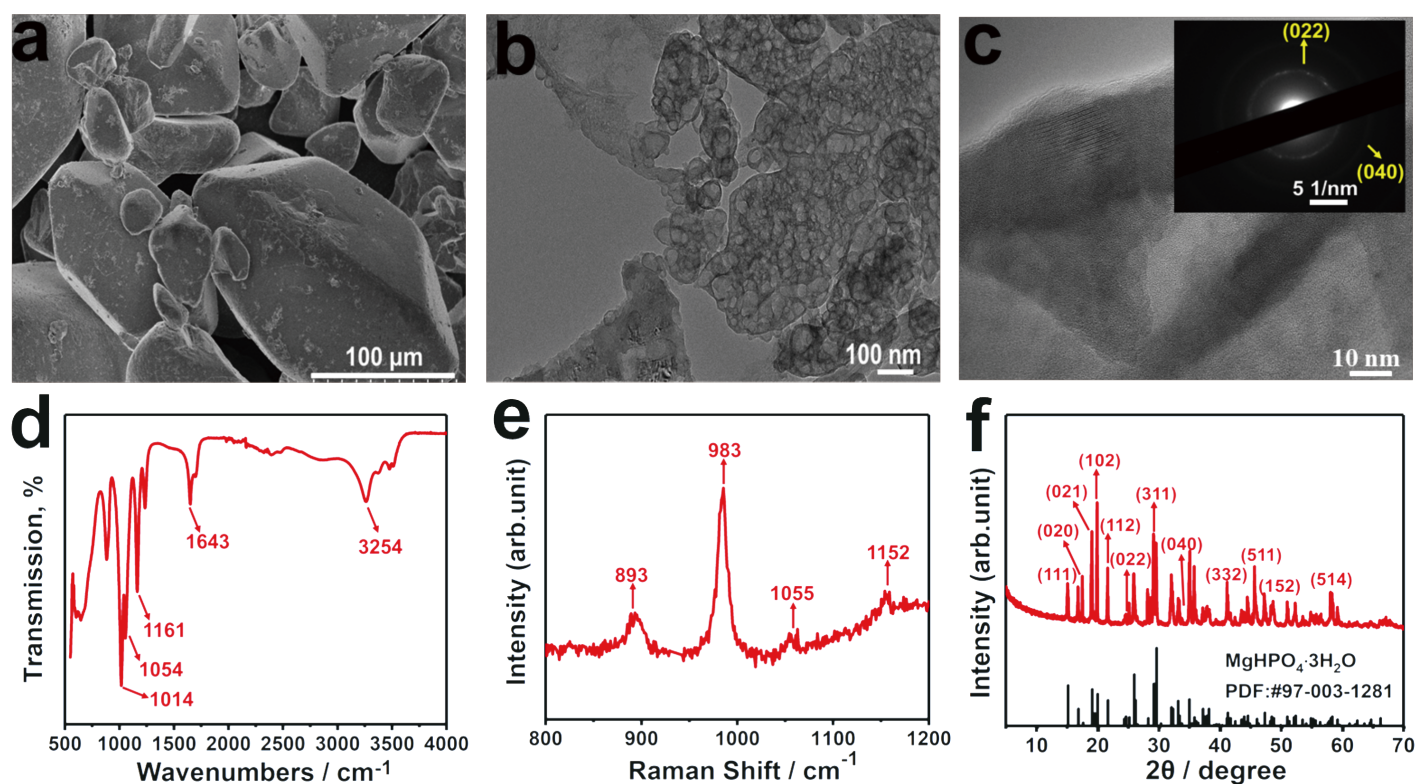

Fig. 1 Characterization of MgP formed on the MWCNT/Nafion electrode. (a) SEM image; (b, c) TEM images with different magnifications, the inset in (c) shows the corresponding electron diffraction pattern; (d) FTIR spectrum; (e) Raman spectrum and (f) XRD pattern.
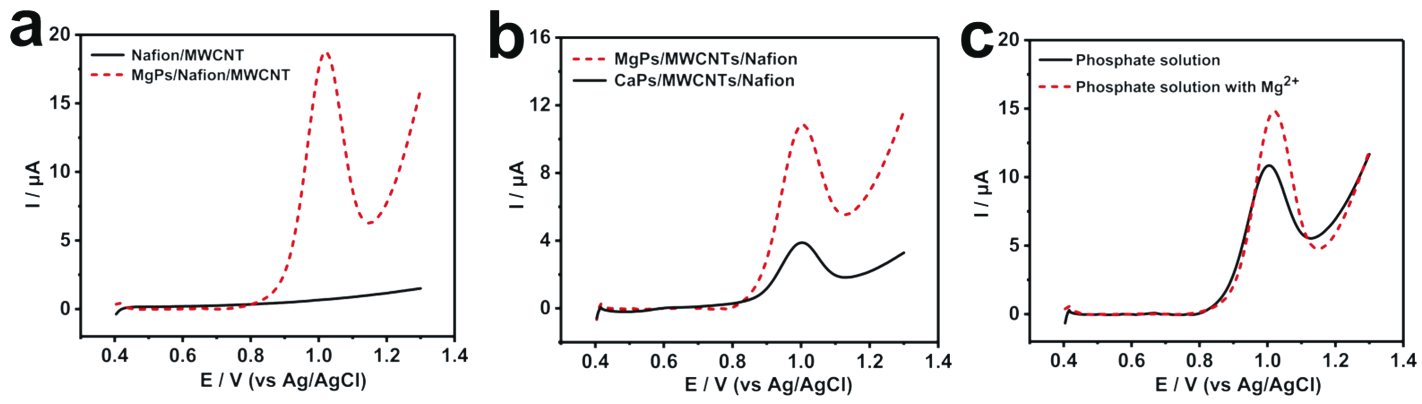

Fig. 2 (a) DPV of MgP/MWCNT/Nafion electrode (dashed line) and MWCNT/Nafion electrode (solid line) in $1 \mathrm{mM}$ phosphate buffer solution at $\mathrm{pH}$ 7.4; (b) DPV of MgP/MWCNT/Nafion electrode (dashed line) and CaP/MWCNT/Nafion electrode (solid line) in $10 \mu \mathrm{M}$ phosphate buffer solution at $\mathrm{pH} 7.4$; (c) DPV of MgP/MWCNT/Nafion electrode in $10 \mu \mathrm{M}$ phosphate buffer solution at $\mathrm{pH} 7.4$ before (solid line) and after (dashed line) the addition of $10 \mu \mathrm{M} \mathrm{Mg}^{2+}$.

with that obtained from the XRD spectra (Fig. 1f), where the (022), (040) planes as well as other planes are also observed in the standard card of newberyite (PDF No. 97-003-1281). The element ratio of $\mathrm{Mg}$ and $\mathrm{P}$ was measured to be approximately 1.0 (Fig. S1), which also agrees with the chemical stoichiometric ratio of $\mathrm{MgHPO}_{4} \cdot 3 \mathrm{H}_{2} \mathrm{O}$. In conclusion, the newberyite $\left(\mathrm{MgHPO}_{4} \cdot 3 \mathrm{H}_{2} \mathrm{O}\right)$ was assembled on the surface of MWCNT/ Nafion successfully, and its prominent hydration feature would provide a crucial fundamental for its subsequent electrochemical investigation.

Electrochemical investigation based on the hydration process of $\mathrm{MgP} / \mathrm{MWCNT/Nafion}$

As a powerful tool to reveal the electrochemical behavior of electrical active material, DPV is widely used in electrochemical studies as well as in phosphate detection..$^{33,34}$ For example, the catalytic hydrogen waves were observed when the molybdenum phosphide modified electrode was subjected to a DPV scan, which was applied for the phosphate detection in blood samples. ${ }^{13}$
Figure 2a shows the typical DPV curves obtained from MWCNT/ Nafion electrode (solid line) and MgP/MWCNT/Nafion electrode (dashed line) in phosphate buffer solution. As can be seen, only the MgP-modified electrode shows the typical oxidation wave, which is similar with that of CaP-modified electrode reported in our previous work. ${ }^{14}$ The transition processes may be described by following Eqs. (1) to (4). In the first step, MgP interact with water to produce coordinated $\mathrm{H}_{2} \mathrm{O}$ due to the hydration effect of $\mathrm{Mg}^{2+}$ in $\mathrm{MgP}$ (Eq. (1)). Upon the addition of phosphate in the equilibrium system, the coordinated $\mathrm{OH}^{-}$is generated sequentially due to the deprotonation effect of phosphate (Eqs. (2) and (3)). The in-situ formed coordinated $\mathrm{OH}^{-}$is believed to be more easily oxidized when compared with their free anion counterparts. ${ }^{35}$ Hence, upon voltage application, the oxygen is released by the oxidation of coordinated $\mathrm{OH}^{-}$(Eq. (4)).

$$
\begin{aligned}
& \mathrm{MgP}+\mathrm{H}_{2} \mathrm{O} \rightleftharpoons \mathrm{MgP}-\mathrm{H}_{2} \mathrm{O} \\
& \mathrm{MgP}-\mathrm{H}_{2} \mathrm{O}+\mathrm{PO}_{4}{ }^{3-} \rightleftharpoons \mathrm{HPO}_{4}{ }^{2-}+\mathrm{MgP}-O H^{-}
\end{aligned}
$$




$$
\begin{aligned}
& \mathrm{MgP}-\mathrm{H}_{2} \mathrm{O}+\mathrm{HPO}_{4}{ }^{2-} \rightleftharpoons \mathrm{H}_{2} \mathrm{PO}_{4}{ }^{-}+\mathrm{MgP}^{-} \mathrm{OH}^{-} \\
& 2 \mathrm{MgP}_{-} \mathrm{OH}^{-}+2 \mathrm{OH}^{-}-4 \mathrm{e} \longrightarrow 2 \mathrm{MgP}+2 \mathrm{H}_{2} \mathrm{O}+\mathrm{O}_{2}
\end{aligned}
$$

As described in the introduction part, $\mathrm{Mg}^{2+}$ should have stronger hydrolysis effect than $\mathrm{Ca}^{2+}$ due to the smaller ion radius (Table S1). The $\mathrm{Mg}^{2+}$ exhibit stronger coordinated ability to $\mathrm{H}_{2} \mathrm{O}$, and the $\mathrm{p} K_{\mathrm{a}}$ of corresponding coordinated $\mathrm{H}_{2} \mathrm{O}$ is about 11.4, which is greater than that of the coordinated $\mathrm{H}_{2} \mathrm{O}$ in $\mathrm{CaP}$ $\left(\mathrm{p} K_{\mathrm{a}}=12.67\right)$. Thus compared with the CaP/MWCNT/Nafion electrode, a more enhanced deprotonation would proceed, leading to a pronounced oxidation wave in the MgP/MWCNT/ Nafion system (Fig. 2b). The presence of free $\mathrm{Mg}^{2+}$ in the bulk solution can greatly affect the electrochemical oxidation response of MgP/MWCNT/Nafion, hence can effectively increase the sensitivity of phosphate detection. As shown in Fig. 2c, a substantially stronger peak was observed for $10 \mu \mathrm{M}$ phosphate in the presence of $10 \mu \mathrm{M} \mathrm{Mg}{ }^{2+}$ when compared with that in its absence. When the phosphate concentration is lower than $10 \mu \mathrm{M}$, it is difficult to observe a clear electrochemical signal in the absence of $\mathrm{Mg}^{2+}$ in the bulk solution. These observations implied that the $\mathrm{Mg}^{2+}$ could promote coordinated $\mathrm{H}_{2} \mathrm{O}$ generation similar to the influence of $\mathrm{Ca}^{2+}$ on $\mathrm{CaP}$ transition, i.e., the interaction of $\mathrm{Mg}^{2+}$ with phosphate even in low concentration can still generate electrochemically detectable coordinated $\mathrm{OH}^{-}$ on the electrode surface. It is believed that $\mathrm{Mg}^{2+}$ plays a vital role to stimulate the transformation of coordinated $\mathrm{H}_{2} \mathrm{O}$ to coordinated $\mathrm{OH}^{-}$. The formation of $\mathrm{Mg}^{2+}$ water complexes has been explored by many previous studies. ${ }^{15,36-40}$ It is known that $\mathrm{Mg}^{2+}$ could form an octahedral complex $\mathrm{Mg}\left(\mathrm{H}_{2} \mathrm{O}\right)_{6}{ }^{2+}$ with water, and the six tightly coordinated water molecules comprise the first layer around the central atom. ${ }^{36}$ Then a second layer is formed, which is composed of twelve less firmly associated $\mathrm{H}_{2} \mathrm{O}$ solvation shells. ${ }^{38-40} \mathrm{Mg}^{2+}$ can activate the coordination $\mathrm{H}_{2} \mathrm{O}$ in the inner layer of $\mathrm{Mg}\left(\mathrm{H}_{2} \mathrm{O}\right)_{6}{ }^{2+}$, so the first layer of coordination $\mathrm{H}_{2} \mathrm{O}$ is more prone to deprotonation. ${ }^{17,40}$ The generated protons are more likely transferred to the free water near the electrode surface to form hydronium. In the presence of phosphate $\left(\mathrm{HPO}_{4}{ }^{2-}\right.$ and $\left.\mathrm{PO}_{4}{ }^{3-}\right)$, the excess hydrodium can be rapidly delocalized, thereby promoting the reaction and generating more $\mathrm{OH}^{-}$on the $\mathrm{MgP} / \mathrm{MWCNT} / \mathrm{Nafion}$, which is subsequently oxidized at a voltage of $1.0 \mathrm{~V} v s$. $\mathrm{Ag} / \mathrm{AgCl}$ during the voltage scan.

\section{Electrochemical conditions optimization for phosphate determination}

To accomplish the phosphate detection based on the hydration process on the MgP/MWCNT/Nafion, the crucial parameters that affect the sensitivity were initially investigated. Figure 3 shows the DPV obtained from $\mathrm{MgP} / \mathrm{MWCNT} / \mathrm{Nafion}$ in $1 \mathrm{mM}$ sodium acetate solution $(\mathrm{pH} 9)$ in the presence of $0.1 \mathrm{mM} \mathrm{Mg}^{2+}$. In the absence of free phosphate in bulk solution, no obvious oxidation peak was obtained. After $1 \mathrm{mM}$ phosphate was added into the solution, the electrochemical oxidation wave could be observed. These observations indicated that the coordinated $\mathrm{OH}^{-}$stimulated from proton acceptors should be responsible for the appearance of the electrochemical oxidation peak. The results also suggest that acetate solution can be used as the appropriate background solution for the phosphate detection. In addition, the acetate solution could tolerate $\mathrm{Mg}^{2+}$ addition with no precipitate during the electrochemical process. It was found that $0.1 \mathrm{mM} \mathrm{Mg}^{2+}$ is optimum for the effective promotion of the DPV peak, and the further increase of $\mathrm{Mg}^{2+}$ concentration exhibited no apparent difference. Therefore, $1 \mathrm{mM}$ acetate solution with $0.1 \mathrm{mM} \mathrm{Mg}^{2+}$ addition was selected as the background electrolyte, which not only maintains an appropriate

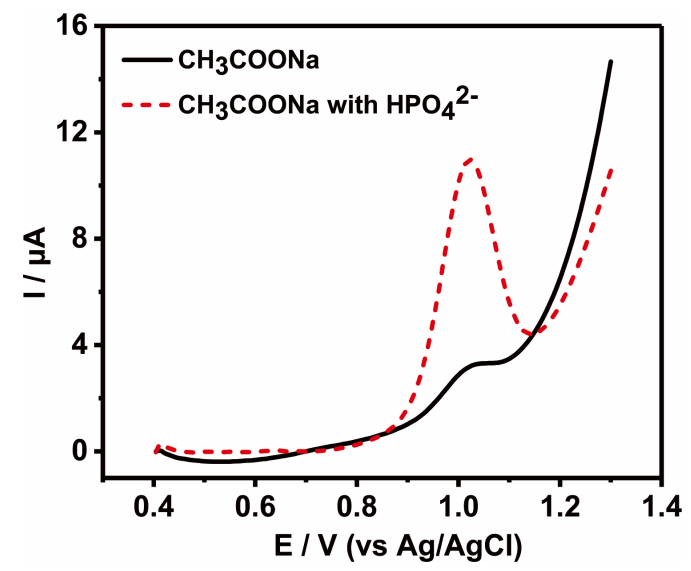

Fig. $3 \mathrm{DPV}$ of $\mathrm{MgP} / \mathrm{MWCNT} / \mathrm{Nafion}$ electrode in $1 \mathrm{mM}$ sodium acetate with $1 \mathrm{mM} \mathrm{HPO}_{4}{ }^{2-}$ (dashed line) and without $\mathrm{HPO}_{4}{ }^{2-}$ (solid line) at $\mathrm{pH} 9$.

ionic strength and $\mathrm{pH}$, but also has no adverse influence on the electrochemical detection of phosphate.

\section{Electrochemical determination of phosphate with $\mathrm{MgP} / \mathrm{MWCNT/}$ Nafion}

A sensitive electrochemical response to phosphate can be obtained with the MgP/MWCNT/Nafion electrode in $\mathrm{pH} 9.0$ acetate solution containing $0.1 \mathrm{mM} \mathrm{Mg}^{2+}$. Figure 4 shows that a good linear relationship between the peak currents and the concentrations of phosphate from 0.01 to $25 \mu \mathrm{M}$ was observed, the calibration curve can be described by the regression equation, $y=13.42-1.331 x\left(R^{2}=0.995\right)$ (Fig. 4b). The limit of detection is estimated to be $32 \mathrm{nM}$ based on the conventional $3 \sigma$ criterion. It is well known that the concentration of phosphate is in the range of $15-40 \mathrm{mM}$ in human urine, and in the range of $5-14 \mathrm{mM}$ in saliva, ${ }^{41,42}$ hence the $\mathrm{MgP} / \mathrm{MWCNT} / \mathrm{Nafion}$ electrode could be a promising sensor for the determination of phosphate concentration in urine and saliva. As shown in Table S2, compared with other phosphate detection methods reported in the literature, our electrode not only exhibits a lower detection limit, but also a wider detection range. It can be seen that $\mathrm{MgP} / \mathrm{MWCNT} / \mathrm{Nafion}$ exhibits good sensitivity with the help of $\mathrm{Mg}^{2+}$. We have also studied phosphate solutions in the concentration range 0.01 to $25 \mu \mathrm{M}$ in the $1.0 \mathrm{mM}$ acetate

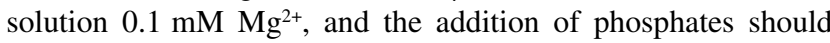
not result in the pH shift (Fig. S2).

Selectivity is also an important factor for the practical application of a sensor. Some potential interferences in body fluid, including $\mathrm{SO}_{4}{ }^{2-}, \mathrm{NO}_{3}{ }^{-}, \mathrm{CO}_{3}{ }^{2-}, \mathrm{Cl}^{-}, \mathrm{Na}^{+}, \mathrm{K}^{+}$and $\mathrm{Ca}^{2+}$ have been tested. As shown in Fig. 5, the species that form easily water soluble compounds with $\mathrm{Mg}^{2+}$ or phosphate have shown no interference for phosphate determination. As shown in Table S3, $\mathrm{CO}_{3}{ }^{2-}$ and $\mathrm{SO}_{4}{ }^{2-}$ can react with $\mathrm{Mg}^{2+}$ to form poor solubility products, hence may exhibit similar electrochemical responses as that of phosphate. Fortunately, no obvious interference was observed for the detection of $1 \mu \mathrm{M}$ phosphate in the presence up to $10 \mu \mathrm{M} \mathrm{C_{3 } { } ^ { 2 - }}$ and $\mathrm{SO}_{4}{ }^{2-}$, presumably because the presence of an excess amount of $\mathrm{Mg}^{2+}$ in bulk solution partially shielded the influence from these species. Up to $1 \mu \mathrm{M}$ level of organic species such as urea, oxalate, uric acid, ascorbic acid and amino acids also show no significant interference on phosphate determination. Considering the concentration of organic substances is substantially lower than that of phosphate in urea and saliva, their interferences would be 

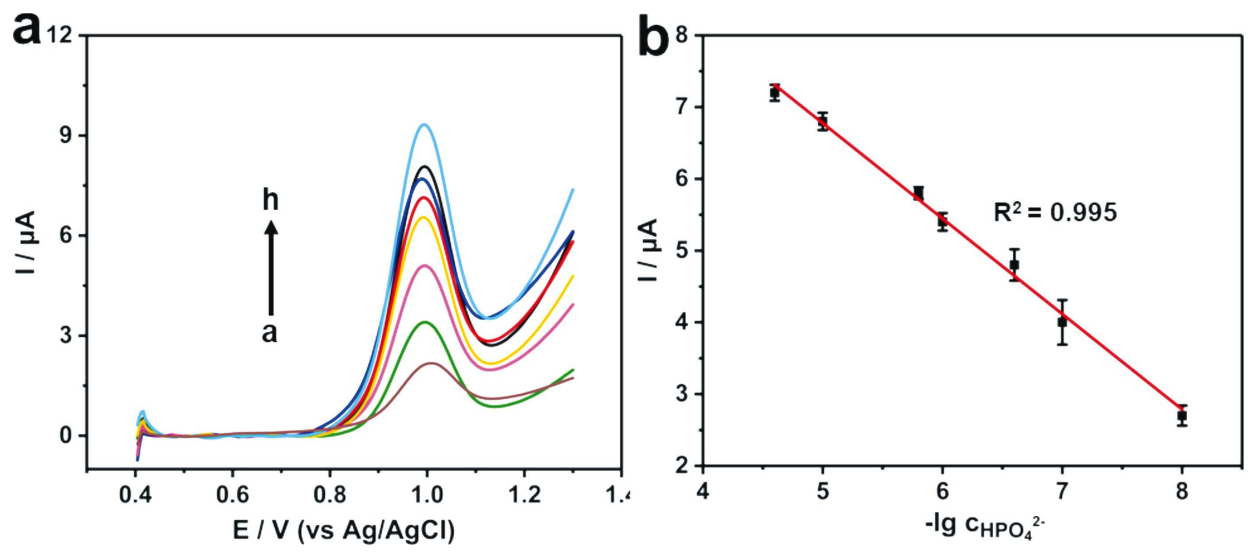

Fig. 4 (a) DPV curves obtained from the MgP/MWCNT/Nafion electrode with a scan rate of $0.1 \mathrm{~V} / \mathrm{s}$. The electrolytic solutions consist of $1.0 \mathrm{mM}$ sodium acetate ( $\mathrm{pH} 9.0)$ in the presence of $0.1 \mathrm{mM} \mathrm{Mg}^{2+}$ and different concentrations of phosphate ions $\left(\mathrm{a}-\mathrm{h}\right.$ respectively represent blank, $1.0 \times 10^{-8}, 1.0 \times 10^{-7}$, $2.5 \times 10^{-7}, 1.0 \times 10^{-6}, 2.0 \times 10^{-6}, 1.0 \times 10^{-5}$, and $2.5 \times 10^{-5} \mathrm{M}$ ); (b) the calibration curve for phosphate analysis based on the DPV method.

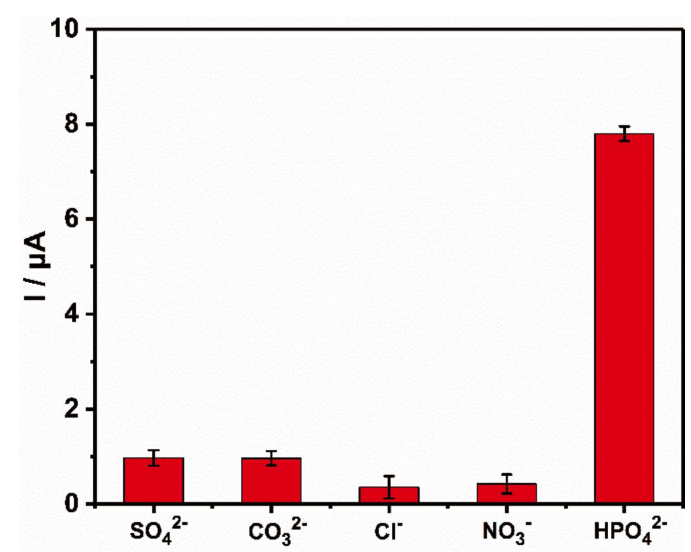

Fig. 5 The anti-interference investigations of the MgP/MWCNT/ Nafion electrode in the presence of $10 \mu \mathrm{M}$ of different anions and $\mathrm{HPO}_{4}^{2-}$.

negligible. The above results prove that the MgP/MWCNT/ Nafion electrode has good selectivity for the detection of phosphate.

\section{The analytical feature of MgP/MWCNT/Nafion in biological} fluids

The phosphate in body fluid plays an essential role, hence the detection of its concentration in urine and saliva is significant for health exams and clinical diagnosis..$^{1,43,44}$ To test the practical applicability, the MgP/MWCNT/Nafion electrode was used to determine the phosphate concentration in human urine and saliva. Due to the presence of high concentrations of phosphate in urine and saliva, a strong electrochemical signal was observed by directly using the $\mathrm{MgP} / \mathrm{MWCNT} / \mathrm{Nafion}$ modified electrode, which exceeded the linear response range of the sensor. Hence, urine and saliva samples were diluted with appropriate amounts of pure water so that obtained DPV signals would fall within the linear calibration range. In the case of the saliva sample, the phosphate was quantified as $11.3 \mathrm{mM}$, while a higher concentration of $25.8 \mathrm{mM}$ was found in the urine sample. The results are consistent with that obtained from ICP-MS analysis,
Table 1 Real sample analysis by using MgP/MWCNT/Nafion and ICP-MS

\begin{tabular}{cccccc}
\hline \multirow{3}{*}{ Sample } & \multicolumn{3}{c}{ MgP/MWCNT/Nafion } & & ICP-MS \\
\cline { 2 - 3 } \cline { 6 - 6 } & $\begin{array}{c}\text { Standard } \\
\text { added/mM }\end{array}$ & $\begin{array}{c}\text { Phosphate } \\
\text { found/mM }\end{array}$ & $\begin{array}{c}\text { Recovery, } \\
\%\end{array}$ & & $\begin{array}{c}\text { Phosphate } \\
\text { found/mM }\end{array}$ \\
\hline Urine & 0 & $25.8 \pm 0.2$ & - & & $26.2 \pm 0.3$ \\
& 4.5 & $30.5 \pm 0.2$ & $104.4 \pm 4.4$ & & $30.9 \pm 0.1$ \\
& 7.5 & $32.9 \pm 0.2$ & $94.7 \pm 2.7$ & & $33.4 \pm 0.2$ \\
Saliva & 15 & $41.2 \pm 0.3$ & $102.6 \pm 2$ & & $41.5 \pm 0.4$ \\
& 0 & $11.3 \pm 0.4$ & - & & $12.1 \pm 0.4$ \\
& 3 & $14.4 \pm 0.1$ & $103.3 \pm 3.3$ & & $14.9 \pm 0.1$ \\
& 5 & $16.1 \pm 0.2$ & $96 \pm 4$ & $16.7 \pm 0.3$ \\
& 10 & $21.6 \pm 0.4$ & $103 \pm 4$ & $21.9 \pm 0.4$ \\
\hline
\end{tabular}

indicating that the sensor is reliable for real sample analysis. To further evaluate the accuracy of the sensor, the phosphate standards were added to the body fluids samples and the satisfactory recoveries of $96-103.3 \%$ for urine and $94.7-104.4 \%$ for saliva were obtained (Table 1). Compared with other reported methods for phosphate detection in the literatures, the present sensor not only has a lower detection limit, but also is simple in preparation and analysis procedure.

Additionally, the MgP/MWCNT/Nafion sensor also showed good stability, as after 10 continuous DPV cycles, the oxidation peaks showed no significant decline (Fig. S3). The relative standard derivation (RSD) of the DPV peak current was $2.28 \%$ for ten tests, which suggested good precision and reproducibility of the MgP/MWCNT/Nafion electrode. After electrochemical measurement, the electrode was rinsed with ultrapure water, and reactivated by incubating in the $1.0 \mathrm{mM} \mathrm{Mg}^{2+}$ and phosphate solution $\left(37.5^{\circ} \mathrm{C}\right)$ for $24 \mathrm{~h}$. In addition, the MgP/MWCNT/ Nafion modified electrode is stable for at least in three weeks when stored in $1 \mathrm{M} \mathrm{pH} 7.4$ phosphate buffer solution.

\section{Conclusions}

In summary, magnesium phosphate was assembled on MWCNT/ Nafion modified GCE to obtained the MgP/MWCNT/Nafion 
electrode. In the presence of phosphate, the coordinated $\mathrm{OH}^{-}$ could be induced from the interplay of hydration and proton transformation in $\mathrm{MgP}$. And the resultant coordinated $\mathrm{OH}^{-}$was verified by the typical oxidation peak at $1.0 \mathrm{~V} v s$. $\mathrm{Ag} / \mathrm{AgCl}$. Under the promotion of free $\mathrm{Mg}^{2+}$, sub $\mu \mathrm{M}$ level phosphate could play the proton acceptor role to enhance the oxidation response of $\mathrm{MgP} / \mathrm{MWCNT} / \mathrm{Nafion}$. Thus, the MgP/MWCNT/ Nafion electrode can be applied for phosphate detection in aqueous solutions. And the analysis for real samples, including human saliva and urine, proves that the as-prepared phosphate sensor also has excellent sensitivity, good selectivity and stability. In this work, we not only constructed a feasible electrochemical platform for phosphate detection in biological systems, but we also gained new insight into the transition process of $\mathrm{MgP}$ in the solid/water interface.

\section{Acknowledgements}

This work was supported by the Natural National Science Foundation of China (51973083), National First-Class Discipline Program of Food Science and Technology (JUFSTR20180301), China Postdoctoral Science Foundation (2019M651688), Fundamental Research Funds for the Central Universities (JUSRP22027), and MOE \& SAFEA for the 111 Project (B13025). Q. S. would like to acknowledge the work of the Central Laboratory, School of Chemical and Material Engineering, Jiangnan University.

\section{Supporting Information}

This material is available free of charge on the Web at http:// www.jsac.or.jp/analsci/.

\section{References}

1. S. Berchmans, T. B. Issa, and P. Singh, Anal. Chim. Acta, 2012, 729, 7 .

2. R. C. H. Kwan, H. F. Leung, P. Y. T. Hon, H. C. F. Cheung, K. Hirota, and R. Renneberg, Anal. Biochem., 2005, 343, 263.

3. W. H. Lee, Y. Seo, and P. L. Bishop, Sens. Actuators, B, 2009, 137, 121.

4. C. Mousty, S. Cosnier, D. Shan, and S. L. Mu, Anal. Chim. Acta, 2001, 443, 1.

5. Y. T. Kong, M. Boopathi, and Y. B. Shim, Biosens. Bioelectron., 2003, 19, 227.

6. S. Berchmans, R. Karthikeyan, S. Gupta, G. E. J. Poinern, T. B. Issa, and P. Singh, Sens. Actuators, B, 2011, 160, 1224.

7. S. Hinkamp and G. Schwedt, Anal. Chim. Acta, 1990, 236, 345.

8. J. Jakmunee and J. Junsomboon, Talanta, 2009, 79, 1076.

9. J. Dong, X. Wang, F. Qiao, P. Liu, and S. Ai, Sens. Actuators, B, 2013, 186, 774.

10. D. Huo, Q. Li, Y. Zhang, C. Hou, and Y. Lei, Sens. Actuators, B, 2014, 199, 410.

11. M. L. Quint, F. S. de Souza, A. Spinelli, and J. B. Domingos, IEEE Sens. J., 2015, 15, 1012.

12. K. Xu, Y. Kitazumi, K. Kano, T. Sasaki, and O. Shirai, Anal. Sci., 2020, 36, 201.

13. J. Zhang, Y. Bian, D. Liu, Z. Zhu, Y. Shao, and M. Li, Anal. Chem., 2019, 91, 14666.
14. S. Sun, Q. Chen, S. Sheth, G. Ran, and Q. Song, ACS Sens., 2020, 5,541

15. A. K. Katz, J. P. Glusker, S. A. Beebe, and C. W. Bock, J. Am. Chem. Soc., 1996, 118, 5752.

16. L.-W. Du, S. Bian, B.-D. Gou, Y. Jiang, J. Huang, Y.-X. Gao, Y.-D. Zhao, W. Wen, T.-L. Zhang, and K. Wang, Cryst. Growth Des., 2013, 13, 3103.

17. A. K. Katz, J. P. Glusker, G. D. Markham, and C. W. Bock, J. Phys. Chem. B, 1998, 102, 6342.

18. F. Tamimi, D. Le Nihouannen, D. C. Bassett, S. Ibasco, U. Gbureck, J. Knowles, A. Wright, A. Flynn, S. V. Komarova, and J. E. Barralet, Acta Biomater, 2011, 7, 2678.

19. M. I. H. Bhuiyan, D. S. Mavinic, and F. A. Koch, Chemosphere, 2008, 70, 1347.

20. L. Wang and G. H. Nancollas, Chem. Rev., 2008, 108, 4628.

21. S. N. Britvin, G. Ferraris, G. Ivaldi, A. N. Bogdanova, and N. V. Chukanov, Neues Jb. Miner. Monat., 2002, 2002, 160

22. S. Sun, S. Sheth, and Q. Song, Electrochim. Acta, 2020, 332, 135477

23. A. Ayad, Y. Naimi, J. Bouet, and J. F. Fauvarque, J. Power Sources, 2004, 130, 50.

24. J. Ma, H.-J. Ni, D.-Y. Su, M.-Y. Huang, and X.-X. Wang, Int. J. Hydrogen Energy, 2012, 37, 13185.

25. G. Lota, K. Fic, and E. Frackowiak, Energy Environ. Sci., 2011, 4, 1592.

26. J. M. Schnorr and T. M. Swager, Chem. Mater, 2011, 23 , 646.

27. D. Liu, L. Mao, and H. Wang, Mater. Lett., 2019, 240, 169.

28. M. Fouladi and A. Amadeh, Electrochim. Acta, 2013, 106, 1.

29. P. Sikder and S. B. Bhaduri, J. Am. Ceram. Soc., 2018, 101, 2537.

30. N. Ostrowski, B. Lee, D. Hong, P. N. Enick, A. Roy, and P. N. Kumta, ACS Biomater. Sci. Eng., 2015, 1, 52.

31. H. B. Mousser, A. Hamoudi, S. Fleutot, S. Fontana, F Cleymand, and A. Mousser, J. Pharm. Investig., 2018, 48 , 575.

32. R. L. Frost, S. J. Palmer, and R. E. Pogson, Spectrochim. Acta, Part A, 2011, 79, 1149.

33. J. Han, R. Fu, C. Jin, Z. Li, M. Wang, P. Yu, and Y. Xie, Microchem. J., 2020, 152, 104356.

34. A. Molazemhosseini, L. Magagnin, P. Vena, and C.-C. Liu, Sensors, 2016, 16, 1024.

35. B. S. Yeo and A. T. Bell, J. Am. Chem. Soc., 2011, 133 , 5587.

36. C. W. Bock, A. K. Katz, and J. P. Glusker, J. Am. Chem. Soc., 1995, 117, 3754.

37. M. Soniat, L. Hartman, and S. W. Rick, J. Chem. Theory Comput., 2015, 11, 1658.

38. C. W. Bock, A. Kaufman, and J. P. Glusker, Inorg. Chem., 1994, 33, 419.

39. Y. Lee, D. Thirumalai, and C. Hyeon, J. Am. Chem. Soc., 2017, 139, 12334

40. O. Allner, L. Nilsson, and A. Villa, J. Chem. Theory Comput., 2012, 8, 1493.

41. J. W. Lowdon, H. Ishikura, A. Radchenko, R. ArreguinCampos, R. Rogosic, B. Heidt, K. Jimenez Monroy, M. Peeters, H. Dilien, K. Eersels, T. J. Cleij, and B. van Grinsven, ACS Omega, 2020, 5, 21054.

42. W.-L. Cheng, J.-W. Sue, W.-C. Chen, J.-L. Chang, and J.M. Zen, Anal. Chem., 2010, 82, 1157.

43. N. Majed, Y. Li, and A. Z. Gu, Curr. Opin. Biotechnol., 2012, 23, 852 .

44. R. K. Shervedani and S. Pourbeyram, Biosens. Bioelectron., 2009, 24, 2199. 